\title{
Company Based on Fairness Concerns Farmers Type Order Contract Mechanism Research
}

\author{
Xidong Deng ${ }^{\mathrm{a}}$, Wennan Zou*, ${ }^{\text {, }}$, Jiaqi Yao ${ }^{\mathrm{c}}$ \\ School of Economics and Management, China Three Gorges University \\ aemail: 1067203988@qq.com, bemail:281278375@qq.com,'email:307797402@qq.com
}

\begin{abstract}
Under the "order contract mechanism of company + farmer" of supply chain of agricultural products and introduce the fair system, studies the influence on the supply chain and the coordination contract as farmers with behavior of fairness concerns This paper establishes two echelon supply chain system composed of the farmers and corporations, analyses the influence on optimal decision as farmers with behavior of fairness concerns in farmers.
\end{abstract}

Keywords- supply chain of agricultural products, fairness concerns, supply chain contract

\section{INTRODUCTION}

With the development of agricultural industrialization in china, agriculture leaders and farmer's contract farming had rapider development. But there are outstanding issues in the process of farmer's contract farming development, such as the lower performance arte of booking farming, the phenomenon of scarcity of credit exist widely. They are not only impact initiative in orders for leading company and farmers, but also impact the development of agricultural and rural economy[1]. How to risen initiative in participation of farmers and company, and how to improve the phenomenon of lower performance arte of booking farming have important implications for promoting the healthy development of agricultural industrialization and the scale management of agricultural.

Although contract farming has widespread use nationwide, we should not ignored the problems that phenomenon exhibits. Such as scarcity of credit exist widely about the order of "company + farmer" which would impact the virtuous cycle of contract farming. On the other hand, a great many experts at home and abroad analyze and research this phenomenon. Some famous people such as Yefei raised a kind of coordination mechanism of agricultural products: "purchase price and subsidizing purchases + protection of market price + cash deposit[2]. Arumugam let the Malaysian peninsula's contract farming as the background, and use stratified sampling method arrived at five elements of influencing the fulfillment rate: an unstable market, market information, technology to boost production, indirect margins and investment[3]. Guohongdong raised that we should keep base acquisitions and fluctuate along with market changes so that we can keep a higher order ate that others[4]. Tuguoping raised a kind of business models called "company +famers+ option of futures", he said that by this business models we could avoid the company's risk and avert default of farmers[5].
Guo and Jolly raised we should keep base price or let the farmers make project investment so that we may improve the rate of booking farming[6]. Lifei analyzed the risk of "company + peasant household" model from incomplete angle and pointed out that the incomplete is the key factor to caused high defaults rate[7]. This research provided a very valuable reference. to solve the high default rate of agriculture in our country.

We assumed these company are full rational, in other words that the company and farmers. According to the research, policymakers are rational, and fairness will influence the decision of policymakers. Tanjiayin said that under the retailer's fair behavior, the revenue-staring contract would influence the result, revenue splits and the wholesale of supply chain[8]. Other people like Dushaofu study the same thing, and they put the phenomenon under the traditional two-stage supply chain[9]. Cui put two elements to the newsboy model: fair and concerns. It is found that if every member in the supply chain has pay attention to the fair, the makers will maximize the supply chain of profit and facilitate the coordination efficiency of supply chain[10]. De Bruyn and Bolton have studied stability and quantify of fair practice for bargaining model.

Therefore, this article based contract farming and created a new contract farming supply chain with "farmers + company"

\section{THE PROBLEM DESCRIPTION AND MODEL ASSUMPTIONS}

This article studied about the influence for production of agricultural products within behavior of fairness concerns, also studied the problem of contract mechanism of agricultural products supply chain which consisting of one company and one of the farmers. Under the cooperation mechanism: "company+ farmers", farmers responsible for the production of agricultural products and company responsible for purchase and sales of agricultural products. In order to ensure the supply of agricultural products and the enthusiasm of the farmers for agricultural production, the company signed a contract for purchase order which both sides agreed. Under this model of purchase order, farmers can depend on themselves putting into the contributed capital. After the end of production season, the company will use "autopilot" to make sure famers' benefit. After the company buying products, the company will process the agricultural products and sales these products as 
market retail. But the market retail is random.

In the whole production process of agricultural products, farmers will invest $e \in[0,1], C(e)$ is the investment costs about the proportion of agricultural inputs. In the normal conditions, we assume cost function $C(e)$ is A second order differentiable single convex function of the proportion of agricultural inputs, also call $\frac{d C(e)}{d e}>0$, $\frac{d^{2} C(e)}{d e^{2}}>0$ . we use $Q=Q(e)$ stands for the agricultural products, because of the agricultural products will increase with the investment costs about the proportion of agricultural inputs, we assume that $Q$ is Strictly concave function of $e$.The company ask the market demand to change by random variables, and its probability density function is $f(\bullet)$, the distribution function is $F(\bullet)$.

$$
\frac{d^{2} \pi_{I}(e)}{d e^{2}}=p(1-F(Q(e))) \frac{d^{2} Q(e)}{d e^{2}}-f(Q(e))\left(\frac{d Q(e)}{d e}\right)^{2}-\frac{d^{2} C(e)}{d e^{2}}
$$

Because of $\frac{d Q(e)}{d e}>0, \frac{d^{2} Q(e)}{d e^{2}} \leq 0, \frac{d^{2} C(e)}{d e^{2}} \geq 0$, $\frac{\partial^{2} \pi_{I}(e)}{\partial e^{2}}$

. The famers' investment of the most level of agricultural inputs $e_{I}^{*}$ need satisfied with $\frac{d \pi_{I}(e)}{d e}=0$. According to above formula we can sure:

$$
\frac{d Q(e)}{d e}=\frac{1}{p(1-F(Q(e)))} \frac{d C(e)}{d e}
$$

\section{$B$ The decentralized decision model}

Under the decentralized decision model, famers decided the best investment to agricultural inputs by their own best interests. If the farmer can keep the "basic acquisition and marketable, the farmers' random benefit function is:

$$
\pi_{F}(e)=\max \left\{\omega_{c}, \omega\right\} Q(e)-C(e)
$$

$\max \left\{\omega_{c}, \omega\right\}$ is the price on the acquisition. The market price on the acquisition of agricultural products' probability density function and distribution function are

$$
\pi_{C}\left(\omega_{c}\right)=p\left(Q(e)-\int_{0}^{Q(e)} F\right.
$$

The second derivative of (9)is:

$$
\frac{d^{2} \pi_{C}\left(\omega_{c}\right)}{d \omega_{c}^{2}}=-g\left(\omega_{c}\right) Q(e)<0
$$

\section{THE BASIC DECISION MODEL}

\section{A. The centralized decision models}

The centralized decision models does not consider the contract prices and the fair share of cooperation-benefits between company and famers, and both of them have interests in common, so they make a decision together which make sure the whole supply chain get the establishing an optimum price. The stochastic function of supply chain system is

$$
\pi_{I}(e)=p \min (Q(e), D)-C(e)
$$

Because of the agricultural products supply depends on the random variables of the demand of agricultural products. Here we rearranges (1), we can get:

$$
\pi_{I}(e)=p\left(Q(e)-\int_{0}^{Q(e)} F(x) d x\right)-C(e)
$$

We also derivative (2) of agricultural inputs, we can get: $g(\bullet), G(\bullet)$ which depend on the interval $[l, u]$. Here we rearranges (5), we can get:

$$
\pi_{F}(e)=\left(u-\int_{\omega_{c}}^{u} G(t) d t\right) Q(e)-C(e)
$$

We make the agricultural inputs' the first derivative and ask the $\frac{d \pi_{F}}{d e}=0$ to get the famers' investment of the most level of agricultural inputs, and by the following equation we can get:

$$
\frac{d Q(e)}{d e}=\frac{1}{\left(u-\int_{\omega_{c}}^{u} G(t) d t\right)} \frac{d C(e)}{d e}
$$

The company decided the best price on the acquisition which can maximize the profit, and the stochastic benefit function is:

$$
\pi_{C}(e)=p \min (Q(e), D)-\max \left\{\omega_{c}, \omega\right\} Q(e)
$$
is:

We rearranges (8) to get the benefit function of company

$$
\begin{gathered}
F(x) d x)-\left(u-\int_{\omega_{c}}^{u} G(t) d t\right) Q(e) \\
\pi_{C}\left(\omega_{C}\right) \text { is the function of bottom price of agricultural } \\
\text { products, } \quad \text { on the other hand, }
\end{gathered}
$$


$\frac{d \pi_{C}\left(\omega_{c}\right)}{d \omega_{c}}=-G\left(\omega_{c}\right) Q(e)<0$

so the company decided the bottom price of agricultural pruducts as the reservation price of farmers sell produce: $\omega_{C}^{*}=\omega_{F}$. At the same time, the company purchase produce should have marginal income. Analyze the (9) we can get that after the produced seasonal, company execute the contract need follow this condition:

$$
\left(u-\int_{\omega_{F}}^{u} G(t) d t\right)<p(1-F(Q(e)))
$$

According to above conclusions, when the condition satisfies the acquisition condition, company will purchase the agricultural production as farmers' reservation price. Combine with the (7), we can get under the decentralized decision, farmers' best investment $e_{d}^{*}$ is:

$$
\begin{aligned}
\frac{d Q(e)}{d e} & =\frac{1}{\left(u-\int_{\omega_{F}}^{u} G(t) d t\right)} \frac{d C(e)}{d e} \\
\text { Ask } \quad \gamma(e) & =\frac{d C(e)}{d e} / \frac{d Q(e)}{d e}, \text { we can get the }
\end{aligned}
$$

derivative of $\gamma(e)$ is:

$$
\frac{d \gamma(e)}{d e}=\frac{\frac{d^{2} C(e)}{d e^{2}} \frac{d Q(e)}{d e}-\frac{d^{2} Q(e)}{d e^{2}} \frac{d C(e)}{d e}}{\left(\frac{d Q(e)}{d e}\right)^{2}}
$$$$
U_{F}=(1+\lambda)\left[\left(u-\int_{\omega c}^{u} G(t) d t\right) Q(e)-C(e)\right]-\lambda\left[P\left(Q(e)-\int_{0}^{Q(e)} F(x) d x\right)-\left(u-\int_{\omega_{c}}^{u} G(t) d t\right) Q(e)\right]
$$

We ask the first derivative of utility function to get:

$$
\frac{d U_{F}}{d e}=(1+\lambda)\left[\left(u-\int_{\omega_{c}}^{u} G(t) d t\right) \frac{d Q(e)}{d e}-\frac{d C(e)}{d e}\right]-\lambda\left[p\left(\frac{d Q(e)}{d e}-F(Q(e)) \frac{d Q(e)}{d e}-\left(u-\int_{\omega_{c}}^{u} G(t) d t\right) \frac{d Q(e)}{d e}\right)\right]
$$

By (16) we can know that the best investment is depends on $\frac{d U_{F}}{d e}=0$, so we can get:

$$
\frac{d Q(e)}{d e}=\frac{1+\lambda}{(1+\lambda)\left(u-\int_{\omega_{F}}^{u} G(t) d t\right)+\lambda\left[\left(u-\int_{\omega_{F}}^{u} G(t) d t\right)-p(1-F(Q(e)))\right]} \frac{d C(e)}{d e}
$$

Conclision1: if the farmer has concern, the agricultural inputs with decentralized decision is $e_{d 1}^{*}<e_{d}^{*}$ We ask

$$
\gamma(e)=\frac{d C(e)}{d e} / \frac{d Q(e)}{d e}=\frac{(1+\lambda)\left(u-\int_{\omega_{F}}^{u} G(t) d t\right)+\lambda\left[\left(u-\int_{\omega_{F}}^{u} G(t) d t\right)-p(1-F(Q(e)))\right]}{(1+\lambda)}
$$




$$
\frac{(1+\lambda)\left(u-\int_{\omega_{F}}^{u} G(t) d t\right)+\lambda\left[\left(u-\int_{\omega_{F}}^{u} G(t) d t\right)-p(1-F(Q(e, f)))\right]}{(1+\lambda)}<\frac{(1+\lambda)\left(u-\int_{\omega_{F}}^{u} G(t) d t\right)}{(1+\lambda)}=\left(u-\int_{\omega_{F}}^{u} G(t) d t\right)
$$

By (13) we can know $\frac{d \gamma(e)}{d e}>0$, in other words, $\gamma(e)$ is an increasing function of $e$. Throw the (19) we can analyze (17) and (12) to get $e_{d 1}^{*}<e_{d}^{*}$

Conclision2: $e_{d 1}^{*}$ is reduction function of $\lambda$. The farmers' concern and agricultural inputs are inverse relationship, in other words, if farmers pay more attention to the coefficient, the investments will be down.

The first derivative of (17) is:

$$
\begin{aligned}
& \frac{d^{2} Q(e)}{d e^{2}} \frac{d e}{d \lambda}=-\frac{\left(p(1-F(Q(e)))-\left(u-\int_{\omega_{F}}^{u} G(t) d t\right)\right)}{\left[\left(u-\int_{\omega_{F}}^{u} G(t) d t\right)+2 \lambda\left(u-\int_{\omega_{F}}^{u} G(t) d t\right)-\lambda p(1-F(Q(e)))\right]^{2}} \frac{d C(e)}{d e} \\
& +\frac{1+\lambda}{(1+\lambda)\left(u-\int_{\omega_{F}}^{u} G(t) d t\right)+\lambda\left(\left(u-\int_{\omega_{F}}^{u} G(t) d t\right)-p(1-F(Q(e)))\right)} \frac{d^{2} C(e)}{d e^{2}} \frac{d e}{d \lambda}
\end{aligned}
$$

By

$$
\begin{aligned}
& \left(u-\int_{\omega_{F}}^{u} G(t) d t\right)<p(1-F(Q(e))), \frac{d C(e)}{d e}>0 \text {, } \\
& \frac{d^{2} Q(e)}{d e^{2}} \leq 0 \text { we can get } \frac{d e_{d 1}^{*}}{d \lambda}<0 \\
& \frac{d \pi_{F}}{d \lambda}=\left[\left(u-\int_{\omega_{F}}^{u} G(t) d t\right) \frac{d Q(e)}{d e}-\frac{d C(e)}{d e}\right] \frac{d e}{d \lambda}
\end{aligned}
$$

Conclision3: the farmers' benefits if reduction functions
By

$\left[\left(u-\int_{\omega_{F}}^{u} G(t) d t\right) \frac{d Q(e)}{d e}-\frac{d C(e)}{d e}\right]>0 \quad \frac{d e_{d 1}^{*}}{d \lambda}<0$ we can get $\frac{d \pi_{F}}{d \lambda}<0$
Conclision4: The Company's benefit is reduction function of coefficient. The company's benefit and farmer's concern are inversely.

We ask the first derivative of (9) in company with decentralized benefits, we get:

$$
\frac{d \pi_{C}}{d \lambda}=\left[p(1-F(Q(e)))-\left(u-\int_{\omega_{F}}^{u} G(t) d t\right)\right] \frac{d Q(e)}{d e} \frac{d e}{d \lambda}
$$

By

$\left(u-\int_{\omega_{F}}^{u} G(t) d t\right)<p(1-F(Q(e))), \frac{d Q(e)}{d e}>0$, $\frac{d e}{d \lambda}<0$, we can get $\frac{d \pi_{C}}{d \lambda}<0$

Conclision5: the whole benefits of company and 
By $\left[p(1-F(Q(e))) \frac{d Q(e)}{d e}-\frac{d C(e)}{d e}\right]>0$,
$\frac{d e}{d \lambda}<0$ we can get $\frac{d\left(\pi_{C}+\pi_{F}\right)}{d \lambda}<0$
Under the farmers' concern, the investment for agricultural is down: $e_{d 1}^{*}<e_{d}^{*}<e_{I}^{*}$. The company and supply chain and farmers' own benefit will be down if the coefficient increase.

\section{CONCLUSION}

This article base on the peculiarity" company + farmers", analyze the influence on agricultural inputs with farmers' concern. It research the contract mechanism of supply chain with farmers' concern. This article analyzes the best investment and benefits of agricultural for company and farmers with farmers' concern. The main conclusion is: if farmers have concern, the best investments of agricultural will be down. At the same time, the benefits of farmers and supply chain will be down if the coefficient increase." Company + farmer", this kind of contract farming has many uncertainties. This article is think about the change and influence of farmers, supply chain system and the agricultural inputs, and does not consider with other factors which may influence farmers, company and supply chain. In the future research, we should think about any factors so we can make a practical programmers for the supply chain model.

\section{CORRESPONDING AUTHOR}

Wennan Zou, 281278375@qq.com, 13872582934

\section{REFERENCES}

[1] Guo weidong, Jiang wenhua. Leading enterprises and farmers of the order arrangement and the performance-A general analysis framework of building and application of order bee industry analysis [J]. Institutional economics research, 2007(01):54-68.

[2] Ye fei, Lin qiang, Li yina. The company based on cvar farmers type order agriculture supply chain coordination contract mechanism [J]. systems engineering., 2011(03):450-460.

[3] Arumugam, Fatimah M A, C CEF. Supply chain analysis of fresh fruits and vegetables (FFV): Prospects of contract farming[J]. Agricultural Economics-Zemedelska Ekonomika, 2010,56(9):435-442.

[4] Guo weidong. Leading enterprises and farmers order arrangement and the performance: Theory and empirical analysis from the zhejiang enterprise [J]. Journal of agricultural economy, 2006(02):36-42+79.

[5] Tu guoping, Leng bibing. Based on a game model of firm farmers model contract stability and optimization [J]. The management science of China., 2010(03):148-157.

[6] Guo H, Jolly RW. Contractual arrangements and enforcement in transition agriculture: Theory and evidence from china[J]. Food Policy, 2008,33(6):570-575.

[7] Li bing. Farmer contract completeness and risk analysis of default [J]. Journal of huazhong university of science and technology (social science edition, 2009(03):97-101.

[8] Tan jiaying, Li bo. Retailers fairness concerns on revenue sharing contract of supply chain coordination effect impact study [J]. China University of Petroleum, DongYing, Shandong, China; 2., 2012(06):118-121.

[9] Du can, Liang liang, Liu tianzhuo. Considering fairness concerns and coordination of supply chain contract $[\mathrm{J}]$. Science and Technology, 2010(11):41-48.

[10] Haitao Cui T, Raju JS, Zhang ZJ. Fairness and channel coordination[J]. Management Science, 2007,53(8):1303-1314.

[11] Zhang yueping. Consider loss aversion and fairness concerns of supply chain coordination problems [J]. Journal of nanjing university of technology (social science edition, 2011(04):69-73.

[12] De Bruyn A, Bolton GE. Estimating the influence of fairness on bargaining behavior[J]. Management Science, 2008,54(10):1774-1791. 